\title{
Comparison of the Prevalence of Comorbidities and its Effects in COVID-19 Patients in China and New York; A Mini Review
}

\author{
Jihui Wang, Huiju Pan and Wei Ouyang* \\ College of Physical Education and Health Sciences, Zhejiang Normal University, Jinhua, Zhejiang, 321004, China \\ *Corresponding author: Wei Ouyang, College of Physical Education and Health Sciences, Zhejiang Normal University, \\ Jinhua, Zhejiang, 321004, China
}

\section{ARTICLE INFO}

Received: 慧 May 22, 2020

Published: 豐 June 05, 2020

Citation: Jihui Wang, Huiju Pan, Wei Ouyang. Comparison of the Prevalence of Comorbidities and its Effects in COVID-19 Patients in China and New York; A Mini Review. Biomed J Sci \& Tech Res 28(1)-2020. BJSTR. MS.ID.004601.

Keywords: COVID-19; Comorbidity; Hypertension; Prevalence; China; New York

\begin{abstract}
The COVID-19 is rapidly evolving. People with COVID-19 have had a wide range of symptoms reported - ranging from mild symptoms to severe illness. Though older age and comorbidities have been reported as risk factors for unfavorable prognosis in COVID-19 patients; it is still less clear so far has been how the number and types of comorbidities influence the patient outcome. However, the comorbidity list could be varied by countries and population from different ethnic background. Based on the above background, we conducted comparative research of prevalence of Comorbidities and Its effects in COVID-19 patients in China and New York, the result showed that the median age of the 4199 patients in China was 51.6 years old, among them 2383 (56.8\%) being male. The most significant pre-conditions are hypertension $(22.7 \%)$, diabetes $(15.3 \%)$, coronary artery diseases (CAD, 14.6\%), chronic obstructive pulmonary disease (COPD, 3.5\%) and malignancies (2.6\%). 29.3\% of the 4199 patients were in severe and critical condition and need intensive care unit (ICU) care. In New York City (NYC), the median age of the patients is 63 years old, and $60.3 \%$ of the patients being male [26]. The most common comorbidities were hypertension (56.6\%), obesity (41.7\%), and diabetes (33.8\%). During hospitalization, among 2634 patients, 373 patients $(14.2 \%)$ (median age, 68 years, $66.5 \%$ male) were treated in the ICU care. While the information of deceased COVID-19 patients $\left(22720,58.2 \%\right.$ male at May $\left.17^{\text {th }}\right)$ in New York (NY) State showed that $94.6 \%$ of the deceased patient were above 50 years old. The top comorbidities with the deceased COVID-19 patients in NY are hypertension (54.2\%), diabetes (35.8\%), hyperlipidemia (21\%), dementia (12.9\%), CAD (11.6\%), renal diseases (10.5\%), COPD (9.1\%), atrial fibrillation (7.6\%), malignancies $(7.3 \%)$. Hypertension is the most prevalent comorbidity in both COVID-19 patients in China and in NY. Patient with one or more of these comorbidities may increase their risk to develop into unfavorable condition. A thorough understanding of comorbidities in COVID-19 patients from different ethnic background may help facilitate the risk management strategies and subsequently medical treatment.
\end{abstract}

\section{Introduction}

COVID-19 is a respiratory condition caused by a coronavirus, and the World Health Organization (WHO) on March 11 declared COVID-19 a pandemic. COVID-19 viral disease now has swept into 213 Countries and Territories around the world according to data issued on May 14 by center for systems science and engineering (CSSE) at Johns Hopkins University. At this moment, the total confirmed cases of the coronavirus COVID-19 are 4,454,038, and death toll jumped to 298,774 around the world. The majority of cases are in China where the virus originated, with 80,430 COVID-19 diagnoses in China before March 11, and Wuhan is the epicenter of coronavirus outbreak. Unfortunately, New York, especially New York City gradually replace the Wuhan as the new world epicenter of COVID-19 outbreak.

Mostly, the COVID-19 victims have pre-existing conditions [16]. However, there is limited information regarding risk factors for severe disease $[3,6,7]$. Based on currently available information 
and clinical expertise, older adults and people of any age who have serious underlying medical conditions might be at higher risk for severe illness from COVID-19 [1-6]. Beside the age, the extending list of other comorbidities at least include hypertension, CAD, diabetes, obesity, cerebrovascular illness, COPD, and kidney dysfunction [1-6]. However, which comorbidity, such as CAD [7, 8], or hypertension [9] is most associated with COVID-19 patient is still remain inconsistency. In present mini review, CAD includes heart failure, atherosclerosis and associated coronary artery disease [7, 8]. Added to these, there is still much ignorance about the nature of COVID-19 virus. Although evidence on the pathophysiology of COVID-19 is rapidly growing, an understanding of the underlying pathological mechanisms which cause some patients to get seriously sick while others experience mild symptoms, remains unexplained $[3,7]$. Therefore, understanding the risk factors for severe disease of the clinical features will increase the efficacy of risk management strategies and subsequently reduce COVID-19 fatal outcomes. In this mini review, we summarized the common comorbidities essentially involved in China, the preceding COVID-19 outbreak epicenter, and in New York, the current virus epicenter in the world.

\section{Method}

This protocol follows the recommendations presented by the Preferred Reporting Items for Systematic Reviews and MetaAnalyses (PRISMA) statement [10]. Relevant literature about China COVID-19 patient information, such as case-control, cohort studies, case reports were included by systematic retrieval of PubMed (Medline), EMBASE, Springer, Web of Science databases until May 19 ${ }^{\text {th }}, 2020$. The searching key words include: "Novel
coronavirus",'Novel coronavirus 2019”, “COVID-19”, “COVID 19”, "2019 nCoV", "Wuhan coronavirus". The New York state deceased COVID-19 patient information was taken from the medical records of Department of Health, New York State, and from center for system science (CSSE) at Johns Hopkins University. Additional COVID-19 spread information was obtained from web sites of Chinese center for disease control and prevention and European Centre for Disease Prevention and Control.

\section{Result}

Data from Chinese center for disease control and prevention (China CDC) shows that whole country is still under pressure of secondary spread of the virus. By May 17, there are 83 confirmed active cases (including 8 severe cases), and 4 suspected cases. The total number of confirmed cases reached to 84044 and caused 4638 deaths. 740,054 close contacts were tracked, and 4,970 close contacts were still under medical observation. Also, there are more 18 cases of asymptomatic infections, 2 of them imported from abroad [11, 12].A total of 16 articles [2, 4, 5, 13-25] about COVID-19 patient information in China were included for descriptive analysis. The main characteristics of comorbidities associated with COVID-19 patient (total number: 4199) in China were presented in Table 1. The median age of the patients was 51.6 years old, among them 2383 (56.8\%) being male. The most significant pre-conditions are hypertension $(22.7 \%)$, diabetes $(15.3 \%)$, CAD (14.6\%), COPD (3.5\%) and malignancies (2.6\%) (Table 1). $29.3 \%$ of the 4199 patients were in severe and critical condition and need intensive care unit (ICU) care.

Table 1: Main Characteristics of Chinese COVID-19 patients included studies.

\begin{tabular}{|c|c|c|c|c|c|c|c|c|c|c|}
\hline \multirow[b]{2}{*}{ Authors } & \multirow[b]{2}{*}{$\begin{array}{c}\text { Patient } \\
\text { No. }\end{array}$} & \multirow[b]{2}{*}{$\begin{array}{c}\text { Mean age } \\
\text { (years } \\
\text { old) }\end{array}$} & \multirow[b]{2}{*}{ Male } & \multicolumn{7}{|c|}{ Comorbidities (\%) } \\
\hline & & & & $\begin{array}{c}\text { Severe ill } \\
\text { (need } \\
\text { ICU)\% }\end{array}$ & Hypertension & Diabetes & CAD & COPD & Malignancies & $\begin{array}{c}\text { Renal } \\
\text { Disease }\end{array}$ \\
\hline Zhangetal. & 140 & 57 & 71 & 41.43 & 30.00 & 12.14 & 10.00 & 1.43 & & 1.43 \\
\hline Zhangetal. & 9 & 36 & 5 & & & 11.10 & & & & \\
\hline Liu et al. & 12 & 53.7 & 8 & & 25.00 & 16.70 & 33.30 & 8.30 & & \\
\hline Chen et al. & 29 & 56 & 21 & & 27.60 & 17.20 & & & 3.40 & \\
\hline Huang et at & 41 & 49 & 30 & 31.70 & 14.63 & 19.51 & 14.29 & 2.44 & 0.62 & \\
\hline Yang et al. & 52 & 59.7 & 35 & & & 17.30 & 9.60 & 7.70 & 3.80 & \\
\hline Xu et al. & 62 & 41 & 36 & 53.23 & 8.06 & 1.61 & & 1.61 & & 1.61 \\
\hline Liu et al. & 77 & 38 & 39 & 14.29 & 10.39 & 6.49 & & 2.60 & 5.19 & \\
\hline Chen et al. & 99 & 55.5 & 67 & 23.20 & & 12.10 & 40.40 & 1.00 & 1.00 & \\
\hline Kul et al. & 137 & 57 & 61 & & 9.50 & 10.20 & 7.30 & 1.50 & 1.50 & \\
\hline Wang et al. & 138 & 56 & 75 & 26.09 & 31.20 & 10.10 & 14.50 & 2.90 & 7.20 & 2.90 \\
\hline Zhou et al. & 191 & 56 & 119 & & 30.37 & 18.85 & 7.85 & 3.14 & 1.05 & \\
\hline Fu et al. & 200 & & 99 & 26.20 & 50.50 & 68.50 & 8.00 & 4.00 & & \\
\hline Hu etal. & 323 & 61 & 166 & 53.25 & 32.50 & 14.60 & 12.70 & 10.22 & 1.50 & \\
\hline Guan et al. & 1099 & 47 & 640 & 15.74 & 15.01 & 7.37 & 2.46 & 1.09 & 0.91 & 0.73 \\
\hline Liang et al. & 1590 & & 911 & 8.20 & 10.00 & 1.00 & & 0.60 & & \\
\hline Mean & & 51.64 & & 29.33 & 22.67 & 15.30 & 14.58 & 3.47 & 2.62 & 1.67 \\
\hline Total No. & 4199 & & 2383 & & & & & & & \\
\hline
\end{tabular}


In a recent case study of 200 COVID-19 patients, Fu et al. reported 37 (23\%) out of 200 patients have at least one comorbidity [4]. The fatality rate is $4.1 \%$ of 49 patients $<49$ years old, $15.1 \%$ of 53 patients in $50-59$ age range, $11.9 \%$ of 59 patients in $60-69$ age range, and $43.6 \%$ of 39 patients $>70$ years old [4]. Move over, the death rate was $52.9 \%$ out of 200 patients in critical condition (need ICU) [4] , and the death rate was 23.0\% in COVID-19 patients with at least one of comorbidities , remarkably higher than $7.69 \%$ in COVID-19 patients without comorbidity [4]. The top 4 fatality rates in patient with COPD (50\%), with hepatic diseases $(22.2 \%)$, hypertension (21.8\%), with diabetes (19\%) [4]. However, in case study conducted by Fu et al., the total COVID-19 patients with COPD are only 8, and COVID-19 patients with hepatic disease are only 9 [4]. Based on their further analysis, hepatic disease diseases were not associated with death risk of COVID-19 patients [4].

In another recent case study conducted by $\mathrm{Hu}$ et al., used the term of "unfavorable" to indicate the COVID-19 patients died, or the condition was getting worse. Among the total 323 patients, 34 $(10.5 \%)$ the patients $(1 / 34$ unfavorable, $2.9 \%)$ are in age range of $20-40,178(55.1 \%)$ patients (25/178 unfavorable, $14 \%)$ are in 41 $65,111(34.4 \%)$ patients (37/111 unfavorable, 33.3\%) are above 65 years old [5]. Among the total 63 COVID-19 unfavorable patients, 27 (42.9\%) patients have hypertension, 19 (30.2\%) have diabetes, 13 (20.6\%) patients have CAD and 9 (14.3\%) patients have CAPD [5]. While in 260 favorable patients discharged, or condition improved, $78(30 \%)$ patients have hypertension, $28(10.8 \%)$ have diabetes, 28 $(10.8 \%)$ patients have CAD and $20(7.7 \%)$ patients have CAPD [5].

Above analysis results indicated the top comorbidities associated with COVID-19 patient in China are hypertension, diabetes, CAD and CAPD. Patient with one or more of these comorbidities may increase their risk to develop into unfavorable condition. Thus, early identification of the comorbidities in COVID-19 patient is of great significance for improving the therapeutic effect of COVID-19 and reducing fatal outcomes.In a recent study of comorbidities, and outcomes among 5700 COVID-19 patients in the NYC Area, Richardson et al., reported that the median age of the patients is 63 years old, and $60.3 \%$ of the patients being male [26]. The most common comorbidities were hypertension (3026, 56.6\%), obesity (1737, 41.7\%), and diabetes (1808, 33.8\%) [26]. During hospitalization, 2634 patients discharged or had died at the study end point, among them, 373 patients (14.2\%) (median age, 68 years, $66.5 \%$ male) were treated in the ICU care [26]. The COVID-19 induced fatality and comorbidity data was obtained from Department Health of NY. The information of 22720 deceased COVID-19 patient (male, 13227, 58.2\%) at May 17 1 th 2020 were included for analysis. $94.6 \%$ of the deceased patient were above 50 years old. The relation of percentage versus age group are $26.2 \%$ in $70-79,25.7 \%$ in $80-89,19.6 \%$ in $60-69,13.5 \%$ in 90 and above, $9.6 \%$ in 50-59. 20390 out of 22720 total fatalities have at least one comorbidity. The main features of comorbidities associated with NY COVID-19 departed patient were presented in table 2 . The significant comorbidities are hypertension (54.2\%), diabetes (35.8\%), hyperlipidemia (21\%), dementia (12.9\%), coronary artery disease (11.6\%), renal diseases (10.5\%), COPD (9.1\%), atrial fibrillation (7.6\%), malignancies (7.2\%) (Table 2). The crude death rate per 100,000 population were 60 Hispanic, 93 Black, 40 White, 47 Asian, 50 Other minorities; while the age-adjusted death rate per 100,000 population were 91 Hispanic, 103 Black, 25 White, 55 Asian, 36 Other minorities.

Table 2: Mean Characteristics of NY State fatality data due to COVID-19.

\begin{tabular}{|c|c|c|c|c|c|c|c|c|c|c|c|}
\hline \multirow[b]{2}{*}{ Age } & \multirow{2}{*}{$\begin{array}{c}\text { Patient } \\
\text { No. }\end{array}$} & \multirow[b]{2}{*}{$\%$} & \multicolumn{9}{|c|}{ Comorbidities (\%) } \\
\hline & & & $\begin{array}{l}\text { Hyper- } \\
\text { tension }\end{array}$ & Diabetes & $\begin{array}{l}\text { Hyperlipid- } \\
\text { emia }\end{array}$ & Dementia & $\begin{array}{l}\text { Hyper- } \\
\text { tension }\end{array}$ & $\begin{array}{c}\text { Renal } \\
\text { Disease }\end{array}$ & COPD & $\begin{array}{c}\text { Atrial } \\
\text { Fibrillation }\end{array}$ & $\begin{array}{l}\text { Hyperten- } \\
\text { sion }\end{array}$ \\
\hline $0-9$ & 4 & 0.00 & 1 & & & & & & & & \\
\hline $10-19$ & 10 & 0.00 & 1 & 2 & & & & & & & \\
\hline $20-29$ & 83 & 0.40 & 12 & 20 & 3 & & & 3 & & & 6 \\
\hline $30-39$ & 306 & 1.40 & 71 & 83 & 18 & & 1 & 21 & 2 & 2 & 6 \\
\hline $40-49$ & 808 & 3.60 & 269 & 249 & 74 & 2 & 21 & 77 & 16 & 10 & 20 \\
\hline $50-59$ & 2185 & 9.60 & 1012 & 857 & 343 & 31 & 138 & 222 & 118 & 46 & 82 \\
\hline $60-69$ & 4452 & 19.60 & 2504 & 1889 & 960 & 163 & 481 & 526 & 357 & 200 & 325 \\
\hline $70-79$ & 5951 & 26.20 & 3577 & 2543 & 1480 & 610 & 810 & 674 & 636 & 450 & 497 \\
\hline $80-89$ & 5845 & 25.70 & 3330 & 1868 & 1312 & 1182 & 861 & 625 & 622 & 659 & 518 \\
\hline$\geq 90$ & 3076 & 13.50 & 1529 & 616 & 575 & 931 & 328 & 229 & 305 & 367 & 200 \\
\hline \multirow{2}{*}{$\begin{array}{c}\text { Total No. } \\
\%\end{array}$} & 22720 & & 12306 & 8127 & 4765 & 2919 & 2640 & 2377 & 2056 & 1734 & 1654 \\
\hline & & & 54.16 & 35.77 & 20.97 & 12.85 & 11.62 & 10.46 & 9.05 & 7.63 & 7.28 \\
\hline
\end{tabular}

\section{Discussion}

COVID-19 can cause symptoms ranging from mild to very severe. For people who have chronic diseases like hypertension, CAD, CAPD and other conditions are more likely infected by the virus, and more likely to develop into severe and critical medical condition. Thus, there is urgent need to do more research on the risk factors which may influences the pathological process of COVID-19 $[3,6,7]$., and more study should be done on why male vs. 
female; people from Hispanic, Black and Asian are more vulnerable to be infected by the virus and at increased risk of dying from covid-19 [3]. Since there are no approved drugs or vaccines for this COVID-19 infection at this time, understanding the risk factors, particularly the preexist medical condition will help to facilitate the current medical treatment and decrease the fatality. The COVID-19 patients from China shows that 2383 (56.8\%) out of total 4199 being male, the percentage is comparable to the male percentage in COVID-19 patients in NYC reported by Richardson et al. [26] and the ratio is similar as the male deceased COVID-19 patients (13227 out of $22720,58.2 \%$ ) in NY. However, the median age of the 4199 patients in China was 51.6 years old, while the patients in NY were older, and the median age is 63 years old. $29.3 \%$ of the 4199 patients in China were in severe and critical condition, and need ICU care, while $14.2 \%$ of the 2634 hospitalized patients in NYC.

In summary of the case report by $\mathrm{Fu}$ et al. [4] and $\mathrm{Hu}$ et al. [5], the highest fatality rate was in COVID-19 patients above 65 years old, the fatality rate is also comparable to the fatality data reported by NY department of health. Accordingly, data from China and NY consistently suggested that male vs. female, older people vs. younger people are in higher risk for COVID-19 infection and more likely to develop into unfavorable conditions. People aged 60 to 70 had double the risk of dying or getting worse as those aged 40 to 60. According to the COVID-19 report in China, the presence of coexisting comorbidities was more common among severe patients compare those with mild condition. The percentage of top 5 comorbidities are hypertension > diabetes > CAD > COPD $>$ malignancies. Based on the report of NY department of health, the geographies of comorbidities associated with COVID-19 departed patient in NY are not fully consistent with the those in China. The percentage of top comorbidities are hypertension $>$ diabetes $>$ hyperlipidemia $>$ dementia $>$ coronary artery disease $>$ renal diseases $>$ COPD $>$ atrial fibrillation $>$ malignancies. Based on the comparation of the comorbidities results in China and in NY patient, hypertension is the riskiest factor in COVID-19 patient from all ethnic backgrounds and need serious consideration when clinical team treat their COVID-19 patients. Since the median age of COVID-19 patients in NYC is 63 years old, and a large portion of the NY deceased patients were in 70 and above (14872 patients, $65.5 \%$ of the total 22720 at May 17th), and the prevalence of dementia is $15 \%$ in people older than 68 years in the United States [27], so it is not surprise to dementia is one of the common comorbidities associated with COVID-19 deceased patient in NY. However, the specific comorbidity and underlie pathology mechanism by which can lead to disease progression still need further investigations.

\section{Conclusion}

Comorbidities are commonly presented in COVID-19 patients in China, and generally found with the deceased COVID-19 patients in NY, USA. Hypertension is the top comorbidity in both COVID-19 patients in China and in NY. A thorough understanding of comorbidities in COVID-19 patients may help facilitate the risk management strategies and subsequently medical treatment. The COVID-19 confirmed cases in NY jumped to 352,845 at May 20th, and only $61886(17.5 \%)$ patients recovered [28]. Therefore, it is important not only for the medical team but also for healthy people, and particularly for people with pre-conditions to learn about risk factors for severe COVID-19 illness. Thus, people can better understand how a medical condition could affect their health if they get sick with COVID-19; can anticipate medical treatment when they get sick and reduce their risk for severe COVID-19 illness by managing any pre-conditions.

\section{Acknowledgement}

This work was supported by grant from Natural Science Foundation of Zhejiang Province (Grant/Award Number: LY20H150001) awarded to Wei Ouyang.

\section{Conflicts of Interest}

The authors have no conflicts of interest to declare.

\section{References}

1. Wang K, Zhang Z, Yu M, Tao Y, Xie M (2020) 15-day mortality and associated risk factors for hospitalized patients with COVID-19 in Wuhan, China: an ambispective observational cohort study. Intensive Care Med.

2. Zhou F, Yu T, Du R, Fan G, Liu Y, et al. (2020) Clinical course and risk factors for mortality of adult inpatients with COVID-19 in Wuhan, China: a retrospective cohort study. The Lancet395(10229): 1054-62.

3. Wise J (2020) Covid-19: Known risk factors fail to explain the increased risk of death among people from ethnic minorities. BMJ369: m1873.

4. Fu L, Fei J, Xiang H-X, Xiang Y, Tan Z-X, et al. (2020) Influence factors of death risk among COVID-19 patients in Wuhan, China: a hospital-based case-cohort study. medRxiv.

5. Hu L, Chen S, Fu Y, Gao Z, Long H, et al. (2020) Risk Factors Associated with Clinical Outcomes in 323 COVID-19 Patients in Wuhan, China. medRxiv.

6. Wang B, Li R, Lu Z, Huang Y (2020) Does comorbidity increase the risk of patients with COVID-19: evidence from meta-analysis. Aging (Albany NY)12(7): 6049-6057.

7. Kowalik MM, Trzonkowski P, Lasinska-Kowara M, Mital A, Smiatacz T, et al. (2020) COVID-19 - toward a comprehensive understanding of the disease. Cardiol J.

8. Caramelo F, Ferreira N, Oliveiros B (2020) Estimation of risk factors for COVID-19 mortality - preliminary results. medRxiv.

9. Tadic M, Cuspidi C, Mancia G, Dell'Oro R, Grassi G (2020) COVID-19, hypertension and cardiovascular diseases: Should we change the therapy? Pharmacological research : 104906.

10. McInnes MDF, Moher D, Thombs BD, McGrath TA, Bossuyt PM, et al. (2018) Preferred Reporting Items for a Systematic Review and Meta-analysis of Diagnostic Test Accuracy Studies: The PRISMA-DTA Statement. Jama 319(4): 388-396.

11. (2020) Chinese center for disease control and prevention. The dynamic information for COVID-19 epidemic.

12. (2020) European Centre for Disease Prevention and Control. Threats and outbreaks: COVID-19 secondary threats and outbreaks: COVID-19.

13. Huang C, Wang Y, Li X, Ren L, Zhao J, et al. (2020) Clinical features of patients infected with 2019 novel coronavirus in Wuhan, China. Lancet 395(10223): 497-506. 
14. Chen N, Zhou M, Dong X, Qu J, Gong F, et al. (2020) Epidemiological and clinical characteristics of 99 cases of 2019 novel coronavirus pneumonia in Wuhan, China: a descriptive study. Lancet 395(10223): 507-513.

15. Chen L, Liu HG, Liu W, Liu J, Liu K, et al. (2020) Analysis of clinical features of 29 patients with 2019 novel coronavirus pneumonia. ZhonghuaJie $\mathrm{He}$ He Hu Xi Za Zhi 43(3): 203-208.

16. Liu K, Fang YY, Deng Y, Liu W, Wang MF, et al. (2020) Clinical characteristics of novel coronavirus cases in tertiary hospitals in Hubei Province. Chin Med J (Engl) 133(9): 1025-1031.

17. Liang W, Guan W, Chen R, Wang W, Li J, et al. (2020) Cancer patients in SARS-CoV-2 infection: a nationwide analysis in China. Lancet Oncol 21(3): 335-337.

18. Zhang MQ, Wang XH, Chen YL, Zhao KL, Cai YQ et al. (2020) Clinica features of 2019 novel coronavirus pneumonia in the early stage from a fever clinic in Beijing. ZhonghuaJie He He Hu Xi Za Zhi 43(3): 215-218.

19. Yang X, Yu Y, Xu J, Shu H, Xia J, et al. (2020) Clinical course and outcomes of critically ill patients with SARS-CoV-2 pneumonia in Wuhan, China: a single-centered, retrospective, observational study. Lancet Respir Med 8(5): 475-481.

20. Wang D, Hu B, Hu C, Zhu F, Liu X, et al. (2020) Clinical Characteristics of 138 Hospitalized Patients With 2019 Novel Coronavirus-Infected Pneumonia in Wuhan, China. Jama323(11): 1061-1069.

21. Guan WJ, Ni ZY, Hu Y, Liang WH, Ou CQ, et al. (2020) Clinical Characteristics of Coronavirus Disease 2019 in China. The New England journal of medicine 382(18): 1708-1720.

ISSN: 2574-1241

DOI: $10.26717 /$ BJSTR.2020.28.004601

Wei Ouyang. Biomed J Sci \& Tech Res

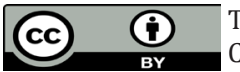

This work is licensed under Creative Commons Attribution 4.0 License

Submission Link: https://biomedres.us/submit-manuscript.php
22. Liu W, Tao ZW, Wang L, Yuan ML, Liu K, et al. (2020) Analysis of factors associated with disease outcomes in hospitalized patients with 2019 novel coronavirus disease. Chin Med J (Engl) 133(9): 1032-1038.

23. Liu Y, Yang Y, Zhang C, Huang F, Wang F, et al. (2020) Clinical and biochemical indexes from 2019-nCoV infected patients linked to viral loads and lung injury. Sci China Life Sci 63(3): 364-374.

24. Xu XW, Wu XX, Jiang XG, Xu KJ, Ying LJ, et al. (2020) Clinical findings in a group of patients infected with the 2019 novel coronavirus (SARS-Cov-2) outside of Wuhan, China: retrospective case series. Bmj368: m606.

25. Zhang JJ, Dong X, Cao YY, Yuan YD, Yang YB, et al. (2020) Clinical characteristics of 140 patients infected with SARS-CoV-2 in Wuhan, China. Allergy.

26. Richardson S, Hirsch JS, Narasimhan M, Crawford JM, McGinn T, et al. (2020) Presenting Characteristics, Comorbidities, and Outcomes Among 5700 Patients Hospitalized With COVID-19 in the New York City Area. Jama.

27. Goodman RA, Lochner KA, Thambisetty M, Wingo TS, Posner SF, et al. (2017) Prevalence of dementia subtypes in United States Medicare fee-for-service beneficiaries, 2011-2013. Alzheimer's \&dementia: the journal of the Alzheimer's Association 13(1): 28-37.

28. (2020) COVID-19 dashboard by center for system science (CSSE) at Johns Hopkins University.

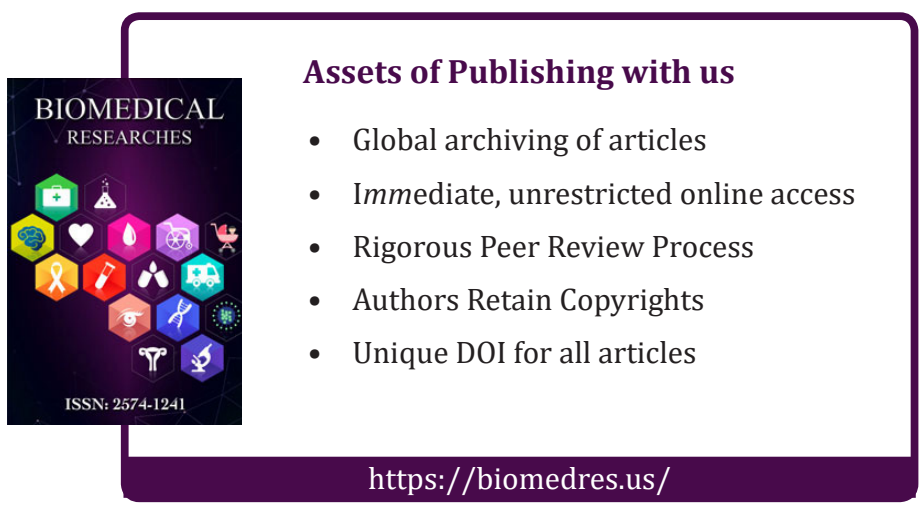

